\title{
CORPOREIDADE NA EDUCAÇÃO DO CAMPO: SABERES DA PRÁTICA DOCENTE NO CONTEXTO AMAZÔNICO
}

\author{
CORPOREITY IN FIELD EDUCATION: KNOWLEDGE OF TEACHING PRACTICE IN \\ THE AMAZON CONTEXT
}

\begin{abstract}
CORPOREIDAD EN LA EDUCACIÓN DEL CAMPO: CONOCIMIENTO DE LA PRÁCTICA DOCENTE EN EL CONTEXTO AMAZÓNICO
\end{abstract}

\author{
Rosenilma Branco Rodrigues \\ Universidade Federal do Oeste do Pará - Brasil \\ Hergos Ritor Fróes de Couto \\ Universidade Federal do Oeste do Pará - Brasil
}

\begin{abstract}
Resumo: Este estudo teve como objetivo investigar a prática docente de professoras que atuam na Educação do Campo na região Amazônica sob a perspectiva da corporeidade. A pesquisa constituiu-se de estudo bibliográfico e de campo. Sobre a pesquisa de campo, a fala das professoras foi o elemento base da análise, a escuta foi realizada sob o aporte da Técnica de Elaboração e Análise de Unidades de Significado, desenvolvida por Moreira, Simões e Porto (2005). A entrevista foi aplicada para oito professoras que trabalham com ensino fundamental menor em uma escola pública do município de Santarém, localizada no território rural ribeirinho. Das professoras pesquisadas, sete possuem mais de dez anos de experiência docente e apenas uma estava iniciando a carreira como professora. A conclusão do estudo mostrou que evidencia-se em muitos elementos do cotidiano escolar a manifestação da corporeidade na prática docente da maioria das professoras investigadas.
\end{abstract}

Palavras chave: Corporeidade. Educação do campo. Prática docente.

\begin{abstract}
This study aimed to investigate the teaching practice of teachers who work in Rural Education in the Amazon region from the perspective of corporeity. The research consisted of a bibliographic and field study. About the field research, the teachers' speech was the base element of the analysis, the listening was performed under the support of the Technique of Elaboration and Analysis of Units of Meaning, developed by Moreira, Simões and Porto (2005). The interview was applied to eight teachers who work with minor elementary education in a public school in the municipality of Santarém, located in the riverside rural territory. Of the teachers surveyed, seven have more than ten years of teaching experience and only one was starting her career as a teacher. The conclusion of the study showed that the manifestation of corporeity in the teaching practice of most of the investigated teachers is evident in many elements of school routine.
\end{abstract}

Keywords: Corporeity. Rural education. Teaching practice. 
Resumen: Este estudio tuvo como objetivo investigar la práctica docente de los docentes que trabajan en Educación Rural en la región amazónica desde la perspectiva de la corporeidad. La investigación consistió en un estudio bibliográfico y de campo. Sobre la investigación de campo, el discurso de los docentes fue el elemento base del análisis, la escucha se realizó bajo el apoyo de la Técnica de Elaboración y Análisis de Unidades de Significado, desarrollada por Moreira, Simões y Porto (2005). La entrevista se aplicó a ocho maestros que trabajan con educación primaria menor en una escuela pública en el municipio de Santarém, ubicado en el territorio rural ribereño. De los maestros encuestados, siete tienen más de diez años de experiencia docente y solo uno estaba comenzando su carrera como maestra. La conclusión del estudio mostró que la manifestación de la corporeidad en la práctica docente de la mayoría de los docentes investigados es evidente en muchos elementos de la rutina escolar.

Palabras clave: Corporeidad. Educación rural. Práctica docente.

\section{Introdução}

Este artigo resulta de uma dissertação de mestrado intitulada Corporeidade e educação do campo: os sentidos atribuídos ao corpo na prática docente nos territórios rurais de Santarém-Pa, realizada como parte das atividades do curso stritu sensu, do programa de pósgraduação em Educação da Universidade Federal do Oeste do Pará. A pesquisa foi financiada pela Coordenação de Aperfeiçoamento de Pessoal de Nível Superior - CAPES.

Ao realizar o estudo neste município, buscou-se contribuir com o melhoramento da educação efetivada na região amazônica compreendendo sua especificidade geográfica, cultural, social, entre outros aspectos tão particulares dessa região.

Poder-se-ia indagar: por que tratar a questão do corpo pode ser tão significativo para a prática do professor? Num olhar mais raso pode parecer simples, mas com profundidade percebe-se que o tema requer melhor tratamento por envolver maior complexidade, pois o corpo dita a condição de existência do ser humano, as interações entre os indivíduos ocorrem também corporalmente, e esse mesmo corpo que rege nosso existir é o mesmo que está em diversos outros espaços sociais. O comportamento humano é manifestado por meio do corpo, assim como ele reage diferente às distintas e variadas formas de tratamento, gerando interferência na formação de cada sujeito. E o professor é uma referência de formação educacional. Logo, de acordo com Cunha (2010), o professor é o ator do processo educativo e qualquer perspectiva de mudança parte dele. Assim, a pesquisa pretendeu problematizar acerca do corpo, no caso deste estudo, o do aluno, e como este é percebido e inserido na prática docente. 
Assim, a corporeidade surge de todas essas questões relacionadas ao corpo. Ela compreende que por meio do corpo - somos, estamos, queremos, sonhamos e podemos. Nesse entendimento cada sujeito é capaz de criar e recriar suas próprias histórias, de projetar-se nas suas próprias inquietações; para a corporeidade, toda a potencialidade humana carece ser colocada em prática, por isso não basta querer, precisa ser e deve estar ativo naquilo que quer. Daí poderia questionar-se: tudo que somos não fomos nós que criamos e/ou escolhemos? Essa indagação denota resposta (s) com outros questionamentos: o que você é? é por que assim você o quis ou alguém decidiu por você? Para essa questão, a resposta cabe a cada indivíduo, pois cada um possui sua própria singularidade, mas de todo modo, elas provocam a reflexão.

A ideia com essas indagações é fazer perceber que cada sujeito é subjetivo e, é, ao mesmo tempo, influenciado pelo mundo exterior, portanto cabe a cada pessoa decidir como esse mundo irá lhe influenciar.

Portanto, discutir a corporeidade no contexto educacional possibilita ao sujeito a construção de sua própria história, fazê-lo vivenciar suas próprias experiências, sua cultura e sua linguagem. O corpo não é apenas uma estrutura orgânica, mas sim a primeira condição de existência e como presença viva não pode ficar inerte diante do mundo, é preciso, então, movimentar-se na intenção de ser autônomo, gerar sentidos, significados, sentimentos, conhecer a si mesmo, a fim de conhecer o outro, os objetos e o ambiente que habita, só assim, pode haver comunicabilidade do eu, com o outro e o mundo.

Contudo, essa discussão da corporeidade que defende a autonomia do sujeito, a humanização das relações sociais, o autoconhecimento, a emancipação do ser humano é relativamente recente na sociedade se considerar a história humana, é somente a partir do século XX que ele passa a ser problematizado como campo de estudo científico. Por outro lado, desde o surgimento da humanidade o corpo é importante para a própria sobrevivência do indivíduo. Pois, “[...] os seres humanos, nos seus primórdios, viveram em pequenos grupos, sobrevivendo da caça e demais recursos naturais (coleta de frutos, raízes, etc.), em constante colaboração e com decisões coletivas entre os seus membros" (SILVA, 2009, p. 92).

Ao longo do crescimento populacional, o corpo vai ganhando outras representações para a sociedade, por exemplo, na antiguidade grega, os filósofos socráticos fragmentaram o ser humano em corpo e alma. Eles atribuíram à alma a função mais importante do sujeito, a racionalidade. Somente através dela haveria possibilidade de inquietação e conhecimento do mundo a sua volta. 
Essa forma de perceber o sujeito foi resgatada mais fortemente no século XX, já na sociedade moderna, quando a teoria do conhecimento racionalista tornou-se a referência na produção dos saberes. Com o apogeu da razão como produtora de todo o conhecimento, o corpo se fez um elemento antagônico nesse cenário. A partir disso, ele foi moldado, oprimido, silenciado, docilizado de acordo com interesses de cada sociedade. Essa concepção estendeuse para as instituições de ensino, o sujeito aprendente é aquele que controla seus desejos, impulsos, paixões, que se mantém quieto e calado, portanto um corpo-objeto, domesticado.

Era um corpo moldado de acordo com a necessidade de cada tempo, de cada época. No século XX essa ideia passa a ser problematizada como uma questão cientifica que colocava em discussão o ser humano como ser capaz de produzir conhecimento, não somente através da razão, mas também, pelas sensações. E que a razão é uma ideia vaga sem o corpo, pois ele auxilia na sua materialização, ao mesmo tempo em que produz outras formas de conhecimento.

O modelo de educação tradicional aderiu a corrente de pensamento racionalista, moldando seus alunos, silenciando-os. Por isso é tão importante discutir a questão do corpo na prática docente, ela, como uma forma de formação humana, necessita estar em constante reflexão sobre as ações que vem desempenhando junto aos alunos a respeito de que tipo de sujeito quer formar. Nesse sentido, Silva (2009) lembra que o espírito do autoritarismo continua intocável dentro da unidade escolar, portanto a escola que ensina, nem sempre reflete sobre a formação do sujeito para viver em sociedade, nem sempre é democrática.

Nesta pesquisa procurou-se discutir acerca da prática docente nos territórios rurais, por ser um espaço onde a ideia de corpo objeto foi fortemente marcada pelo descaso, em especial das políticas públicas, ao sujeito do campo, que foi visto como expressão de mão de obra barata. Cabe salientar que para atender as necessidades capitalistas, os camponeses eram explorados sem a menor preocupação com a dignidade humana. No entendimento de Silva (2009, p. 99) "para o Estado brasileiro, o ensino para todos significava mão-de-obra qualificada para o progresso do capitalismo no Brasil”.

Essa realidade segue outra trajetória, à medida que o sujeito do campo percebe-se como ser de direitos, usando como ferramenta de mudança a luta social e a educação. Portanto, refletir cientificamente sobre a educação nesses territórios, representa formas de fortalecimento de uma educação transformadora e emancipadora, e é com isso que este estudo pretende contribuir.

\section{Corporeidade, Educação do campo e prática docente}


O corpo, primeira forma de existência humana, é um território biológico, e, ao mesmo tempo um simbólico campo de forças que não cessa de inquietar-se e confrontar-se constituindo o mais sublime traço de memória da vida. Podendo revelar diversos delineamentos de subjetividade e fisiologia, mas ao mesmo tempo, também escondê-los. Assim, o corpo está para além de uma matéria orgânica, compreende-se como uma estrutura biocultural (SANT'ANNA, 2001).

A concepção do corpo humano vai desde uma abordagem de corpo-objeto, quando está subjugado ao controle de acordo com interesses do contexto, a uma nova compreensão, corpo-sujeito.

Um corpo não é apenas um corpo. É também o seu entorno. Mais do que um conjunto de músculos, ossos, vísceras, reflexos e sensações, o corpo é também a roupa e os acessórios que o adornam, as intervenções que nele se operam, a imagem que dele se produz, as máquinas que nele se acoplam, os sentidos que nele se incorporam, os silêncios que por ele falam, os vestígios que nele se exibem, a educação de gestos [...] enfim, é um sem limite de possibilidades sempre reinventadas e a serem descobertas. Não são, portanto, as semelhanças biológicas que o definem, mas, fundamentalmente, os significados culturais e sociais que a ele se atribuem. (GOELLNER, 2003, p. 29).

A premissa da corporeidade consiste em olhar o indivíduo como um ser complexo na sua individualidade, assim como no coletivo. Para Moreira et al (2006) é importante entender que a complexidade envolve o conhecimento multidimensional, sabendo que a complexidade surge como dificuldade, como incerteza, e não como uma clareza ou uma resposta; assim como defendem uma corporeidade aprendente, uma ideia de corpo ativo, que não significa estabelecer uma receita para todas as respostas, mas instigar ao desafio, a motivação para o ato de pensar. De acordo com Inforsato (2006) - à medida que as sociedades se tornaram mais complexas, a educação também se tornou.

Destarte, a “[...] educação da corporeidade aprendente neste novo século, exige a complexidade do pensar, em que o uno e múltiplo, certo e incerto, lógico e contraditório estão em íntima relação, sempre incluindo o observador na observação realizada" (MOREIRA et al, 2006, p. 142-143).

Em se tratando de educação, vale ressaltar a afirmação de Assmann:

[...] a corporeidade não é fonte complementar de critérios educacionais, mas seu foco irradiante e primeiro e principal. Sem uma filosofia do corpo, que perpasse tudo na educação, qualquer teoria da mente, da inteligência, do ser humano global enfim, é, falaciosa, de entrada (2012, p. 150). 
Ao defender a teoria da corporeidade, a autora Nóbrega (2010) adverte que esta deve estar atenta para multiplicidade de sentidos dos saberes sobre o corpo, sem a preocupação de fragmentação e reducionismo, mas permitir diferentes aproximações e abordagens, que valorize o diálogo e a comunicação entre os elementos que configuram esse universo multifacetado. Assim:

A reflexão sobre o corpo e a proposição de elementos para uma teoria da corporeidade envolvem questões amplas, muitas delas ainda sem solução ou definição completa. No entanto, é importante exercitar o espírito reflexivo e investigativo, no sentido de gerar atitudes propositivas para enfrentar os desafios da pesquisa e do conhecimento sobre o corpo. (NOBREGA, 2010, p. 36).

Portanto, investigar acerca do corpo na prática docente, significa refletir a respeito da complexidade que envolve todo o processo de ensino aprendizagem. Segundo Cunha (2010), as instituições educativas são constantemente desafiadas a promover uma nova concepção de ensino, que consiga estabelecer relações entre conhecimento e a vida cotidiana do aprendiz. Evidenciando, “[...] a necessidade de oferecer uma educação que promova a vida e a socialização da aprendizagem, redesenhando as escolas, de forma criativa e inovadora, para que atendam às demandas por uma aprendizagem significativa” (CUNHA, 2010, p. 124).

Consequentemente, "é vivendo e agindo na escola que nos preparamos para viver e agir fora da escola, independentemente dos programas e dos objetivos pedagógicos" (Perrenoud, 1995, p. 28).

A relação professor/aluno ainda está fortemente marcada pela ideia de ensino aprendizagem com qualidade, advindo da perspectiva da pedagogia tradicional na qual a responsabilidade por tal resultado centrava-se no papel do professor. Para os autores Costa, Akkari e Silva (2011, p. 77) “[...] a temática da qualidade da educação tem suscitado um intenso debate entre os pesquisadores e gestores políticos acerca das dimensões definidoras de uma educação de qualidade". Os autores ainda advertem que a promulgação da LDB foi importante instrumento que obrigou a ampliação da educação básica, desde a educação infantil ao ensino médio aumentando a responsabilidade do estado com a educação pública.

Contudo, o aumento dos dados numéricos não implica melhoria automática na qualidade do sistema educacional. Outro ponto levantado por eles é que, "[...] cada vez mais a responsabilidade pelo sucesso ou insucesso escolar tem sido atribuída ao professor, entretanto, não têm sido criadas as condições necessárias para o desenvolvimento de seu trabalho na escola" (COSTA, AKKARI E SILVA, 2011, p. 77).

Sobre a realidade da escola Perrenoud adverte que: 
[...] a centração no programa, a avaliação, os métodos ou os meios de ensino ofuscam a realidade da vida quotidiana da escola, que é feita de tudo o que fundamentalmente interessa aos seres humanos: ser amado, aprovado, encontrar o seu lugar, exercer uma influência, arquitectar e realizar projetos, falar de si. (1995, p. 29).

Os novos paradigmas educacionais preconizam que se faz necessário um movimento dialético na relação educador e educando para que a formação escolar traga contribuições para a formação humana.

Nesta conjuntura, há de um lado um modelo tradicional fortalecido pela padronização da educação e de outro os novos paradigmas que se fundamentam na heterogeneidade, no qual o corpo faz parte também desse processo, pois é por meio dele que as pessoas se interrelacionam e vivem em coletividade. Esses dois modelos revelam realidades muito distintas que exigem comportamentos e concepções diferentes, mas que se manifestam sempre em torno dos sujeitos professor e aluno.

Freire (2016) reflete a respeito da grande responsabilidade que é ser professor, sua prática é eminentemente formadora e pode defini-lo pela maneira como a realiza. Sua presença em sala de aula é capaz de ser tão significativa que está passível de análise pelos alunos. Por exemplo, docentes autoritários, competentes, amorosos, frios, racionalistas, cada um destes registra nos discentes uma ou várias impressões. Sua prática é sempre carregada de múltiplos sentidos, seja para o ensino, como para a aprendizagem.

Portanto, é necessário compreender as mudanças que podem ocorrer no contexto escolar, neste sentido, é preciso entender, apoiar, incentivar e promover a formação de professores como importante momento de reflexão docente acerca dos seus valores, teorias subjacentes, práticas e circunstâncias suscetíveis de transformações. Essas condições são fundamentais para introduzir modificações no processo educacional que possibilitarão ao professor encontrar melhores formas de pensar a ação docente refletindo diretamente no processo de ensino e aprendizagem do aluno, assim como na disposição, motivação e bem estar gerado no trabalho do professor (CORRADINI E MIZUKAMI, 2011).

Entretanto, observa-se que no modelo tradicional de educação, o papel do professor está centralizado na formação técnica e, neste sentido, os alunos devem assumir uma homogeneização na sala de aula, a fim de garantir "melhores" resultados, os quais são mensurados pela "avaliação tradicional (hegemônica ainda no final do século XX) fundamentase nos paradigmas do empirismo. Mas não há como congelar, dissecar, mumificar o aluno, o sujeito, para determinar o que ele sabe, o que ele é” (BAGGIO; VIEIRA, 2009, p. 81). 
Essa realidade de aprisionamento do ser humano é uma questão bastante evidente na educação desenvolvida para os camponeses, por um longo período de suas vidas, o tratamento que lhes era dispensado, considerava-os como sujeitos menosprezados, que tinham vida inferior no campo, que serviam apenas para produzir riquezas e alimentos para os centros urbanos. Não tinham acesso à escolarização nem a profissionalização. A falta de assistência governamental, de políticas públicas, muitas vezes pautadas no motivo das localidades serem longínquas.

Quando a educação chegou para esses indivíduos foi um modelo que não pretendia torná-los críticos da própria realidade, pois se assim fosse, perceberiam como eram explorados e questionariam as próprias condições de vida e, assim, poderiam gerar mudanças práticas. Silva (2009, p. 103) alerta que "a formação da consciência crítica é insuficiente. Para mudar é preciso força e os oprimidos só serão fortes se forem organizados”.

A educação recebida no campo fora a mesma implantada nas cidades. A realidade dos camponeses passou a configurar-se diferente, quando eles se organizaram socialmente e buscaram uma educação que atendessem suas especificidades rurais. O movimento em defesa de uma educação do campo, para os sujeitos do campo, foi ganhando maior expressão com adesão das universidades, dos pesquisadores e maior participação dos movimentos sociais. Quando eles buscaram uma educação do e no campo não tinham a intenção de isolar o sujeito camponês, mas de fortalecer seus direitos e fazer perceber a importância de suas atividades para o desenvolvimento social, cultural, político e econômico.

O que queremos chamar a atenção, pois, é que a premissa do vínculo entre campo e educação, entre projeto de campo e projeto de educação, essencial à concepção da Educação do Campo, pode também nos fazer cair na armadilha da visão liberal de educação. A chamada "educação rural" já foi isso: uma visão pragmática e instrumentalizadora da educação, colocada a serviço das demandas de um determinado modelo de desenvolvimento de campo. Isso não tem nada de emancipatório: e ainda menos quando se trata de uma visão setorial de desenvolvimento ou da lógica dominante de pensar a produção apenas na dimensão do negócio. (CALDART, 2008, p. 50).

De acordo com Fonseca e Mourão (2012), o termo “educação rural” não cabe mais no território camponês, pois representa um modelo de educação projetado e executado pelas elites dominantes, no qual os sujeitos camponeses eram vistos e tratados simplesmente como corposobjetos, em benefício do mercado capitalista.

Portanto, a crítica que se faz à educação tradicional é que ela nega a diversidade cultural e social dos alunos, apresenta uma visão linear de educação como se todos participassem de uma única estrutura social e o aprendizado acontecesse de forma padronizada. 
Esse modelo não enxerga a condição complexa dos sujeitos, o corpo não possui significações, suas expressões representam obstáculo para o desenvolvimento das aulas e podem levar ao mal estar docente ${ }^{1}$.

Por isso, os novos paradigmas educacionais buscam evidenciar que os aspectos culturais e sociais são fundamentais na formação humana e a escola tem responsabilidades nesse processo. E quando se fala de seres humanos, deve-se considerar às suas manifestações corporais, já que por meio delas vive-se.

$\mathrm{Na}$ formação educacional, o professor tanto no ambiente escolar, quanto no da família e também para a sociedade em geral, é um dos principais agentes imbuído de muitas responsabilidades, inclusive de promover, provocar e desenvolver a formação do sujeito crítico que, por meio do conhecimento, é capaz de gerar mudanças em si e no meio onde vive. Seu “[...] principal recurso [...] é a postura reflexiva, sua capacidade de observar, de regular, de inovar, de aprender com os outros, com os alunos, com a experiência, construindo, cada vez mais, situações diversificadas nas quais alunos diferentes possam aprender" (CORRADINI; MIZUKAMI, 2011, p. 54).

Atualmente, com a dinâmica do mundo contemporâneo, a velocidade com que os diversos setores da sociedade evoluem não se espera que as pessoas amparem-se apenas nos conhecimentos básicos adquiridos como se estes fossem suficientes para provê-los para o restante de suas vidas, logo, para que não haja prejuízos pessoais e profissionais, é fundamental que se busque uma atualização constante de saberes (CORRADINI; MIZUKAMI, 2011).

Nota-se que,

[...] de repente, as estratégias que tinham dado boas provas tornam-se ineficazes e os alunos devem inventar outras novas: pedia-se-lhes para se calarem, agora pede-se-lhes que se exprimam; convidavam-nos a não se aventurarem a falar a não ser quando tivessem certezas, agora dá-se valor aos seus ensaios e erros; insistia-se sobre a precisão e o conformismo, agora elogia-se a imaginação; elogiava-se o trabalho solitário, agora insiste-se na cooperação. (PERRENOUD, 1995, p. 22-23).

Sabe-se que a docência é repleta de muita complexidade para lograr o ensino, principalmente, pelo que os autores Fernandes; Akkari; Silva (2011) constataram em seus estudos quando afirmaram que existe uma desconexão entre a formação acadêmica e o trabalho docente, ou seja, exige-se do professor conhecimentos e habilidades além dos conhecimentos

\footnotetext{
${ }^{1}$ Mal estar docente, refere-se às relações de conflitos e angústias no oficio de ser professor. Ler mais em: KUENZER, A. Z. As relações entre conhecimento tácito e conhecimento científico a partir da base microeletrônica: primeiras aproximações. Educar, Curitiba, Especial, p. 43-69, 2003. Editora UFPR. P. 43-68.
} 
teóricos adquiridos na universidade. Perez (2012) acrescenta ainda que é atribuída a escola a preparação da criança para desenvolver-se em uma complexa vida moderna. Nessa conjuntura, o professor tem que se reinventar continuamente.

\section{Metodologia}

O estudo foi de natureza qualitativa, organizado em duas etapas: pesquisa bibliográfica e de campo. Para a produção e análise dos dados, utilizou-se da Técnica de Elaboração e Análise de Unidades de Significado, desenvolvida por Moreira, Simões e Porto (2005). A Técnica consiste de três momentos: relato ingênuo; identificação de atitudes e a interpretação.

Esse primeiro momento se deu pela entrevista semiestruturada, com pergunta geradora: O que é ser professor nos territórios rurais? O segundo momento referiu-se a seleção das unidades de significados a partir dos relatos que foram organizados conforme o quadro 01 .

O terceiro momento ocorreu no ato da análise das unidades de significado no qual o referencial ajudou na sustentação e/ou confrontação de ideias.

Foram utilizados dois critérios para a seleção dos sujeitos da pesquisa: estar como professor (a) do ensino fundamental, séries iniciais, e atuar na escola do campo na comunidade Lago Grande do Curuai. A produção final do estudo contou com oito professoras que atenderam aos interesses deste trabalho. Foram seguidos os aspectos éticos da pesquisa com assinatura dos Termos de Consentimento Livre e Esclarecido - TCLE, mantendo o sigilo dos nomes de batismo ou cartório, foi solicitado a cada professora escolher o nome com o qual desejaria ser identificadas na pesquisa. Conforme descrição do quadro 01, os nomes definidos foram: Tânia, Pajurá, Mary, Bem-te-vi, Helen, Eva das Rosas, Violeta e Maria. A entrevista foi aplicada na escola onde as professoras trabalham, sendo realizada separadamente uma da outra.

\section{Com a palavra - as professoras do campo}

$\mathrm{Na}$ indagação, “o que é ser professor nos territórios rurais?” pretendeu-se extrair das professoras o significado da sua prática no dia a dia, os possíveis desafios, a maneira como ela é desenvolvida junto aos alunos, ressalta-se que cada docente respondeu livremente e ordenou sua própria fala.

Quadro 1 - Unidade de significado referente à questão: “O que é ser professor nos territórios rurais?" 


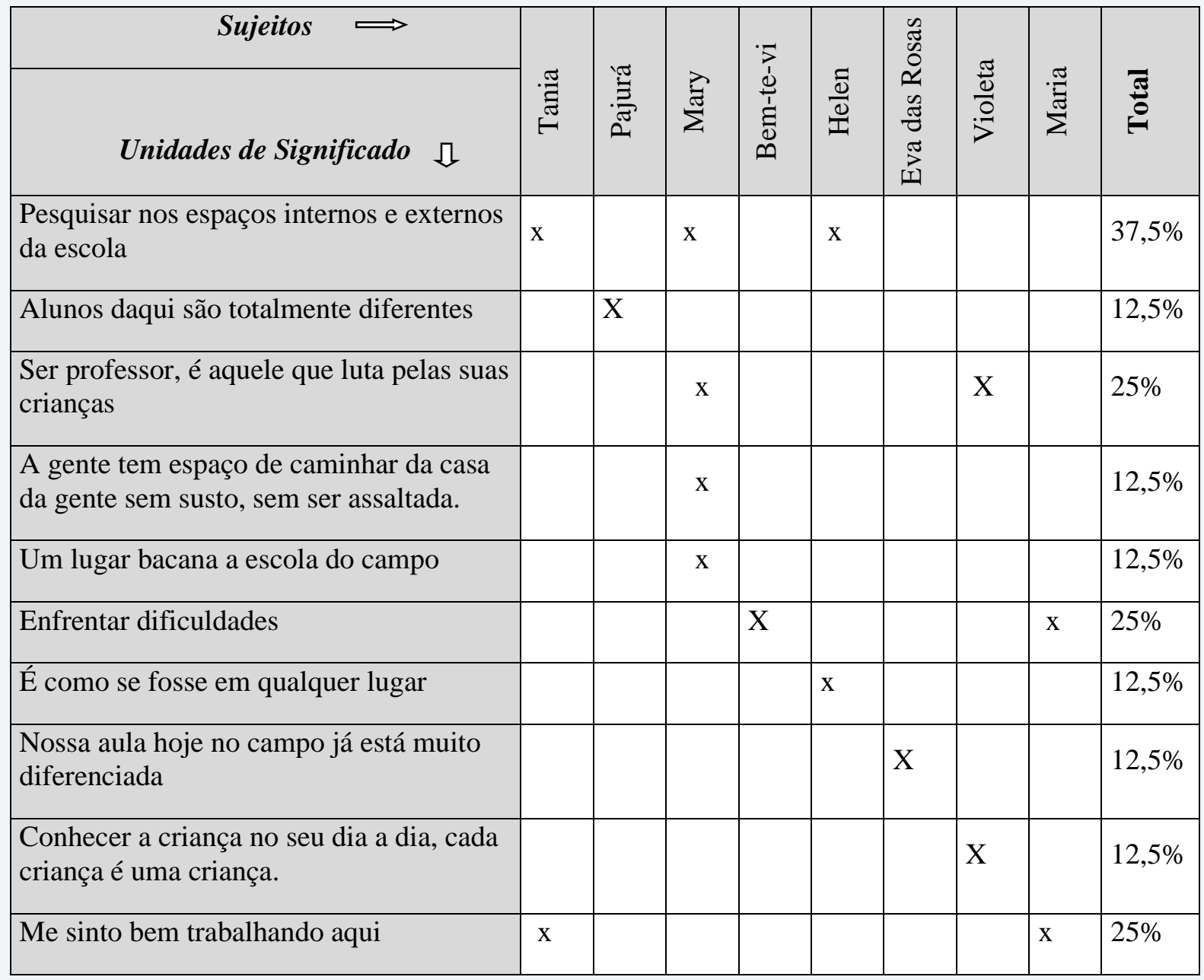

Fonte: Os autores (2017).

Conforme relatado por $37,5 \%$ das entrevistadas, ser professor é poder fazer pesquisas nos espaços internos e externos da escola, conforme destacado por elas:

[...] eu uso os espaços fora da sala de aula [...] principalmente quando tem assunto que vem que é para gente fazer pesquisa no ambiente escolar dos alunos, visitar as plantas como uma aula de ciências, nós temos fonte de pesquisa aqui dentro da sala de aula, sala, espaço aqui como as plantas, as árvores, aqui nós temos bem material para a gente fazer pesquisa com as nossas crianças (MARY).

[...] se tornará mais fácil na hora de desenvolvermos nossa atividade, no caso trabalhar a disciplina de ciências, nós temos como trabalhar fora de uma sala de aula, nós temos como trabalhar sobre a água mostrando o igarapé, no caso se torna mais fácil nós nos deslocarmos do lugar, do local do nosso trabalho, da sala de aula fechada (HELEN).

As professoras relataram que ter mais contato com a natureza viabiliza a promoção de atividades que explorem os espaços externos às salas de aulas, pois possibilita a diversificação das aulas, além do contato direto que a criança pode ter com os igarapés, praias, árvores e animais, permitindo-lhe a relação da teoria com a prática. Sobre o ensino de ciências na 
educação básica, os autores Silva; Ferreira; Viera (2017, p. 301) asseguram que: "o eixo principal é a interação do ensino científico com questões cotidianas para a formação de cidadãos críticos, reflexivos e conscientes de sua condição no mundo e que utilizarão os saberes adquiridos durante o processo de escolarização em suas ações diárias".

As professoras acreditam que por meio dessas experiências, os alunos estabelecem contatos com as diferentes áreas de conhecimento a partir da realidade deles, a ribeirinha:

Nas comunidades rurais-ribeirinhas a cultura amazônica, além do espaço escolar, é expressa na «cultura da conversa», oralidade dos mais antigos, que se utilizam dos espaços comunitários e religiosos para a transmissão dos saberes, dos valores e da tradição social das populações locais, configurando uma prática na qual a cultura é fundamental no processo de formação social dessas comunidades (OLIVEIRA; SANTOS, 2007, p. 1).

Neste aspecto, o ribeirinho tem seus próprios modos de produção material, seja por meio do contato com a água, com a terra ou com a mata. Ele movimenta um conjunto de saberes, de estratégias e de recursos da comunidade. Contudo, essas peculiaridades são silenciadas pelo currículo oficial que é materializado pelas instituições escolares presentes no contexto amazônico (LIMA, 2013).

Para $25 \%$ das professoras, ser professor do campo é aquele que luta pelas suas crianças, conforme pontua Mary,

[...] ser professor é [... ] investir nas minhas crianças, olhar lá o lado da minha criança procurar pesquisar, procurar correr atrás de algo que venha beneficiar eles [...].

A fala da professora Mary revela que o professor deve se dedicar aos alunos, buscando proporcionar-lhes atividades que venham contribuir com o seu desenvolvimento. Por isso, o educador deve munir-se de pesquisa e formação pedagógica, pois tais fatores facilitam para que o docente se torne um investigador da própria prática.

O professor reflexivo é capaz de analisar sua própria prática, avaliar diferentes situações de ensino que não podem ser resolvidas por meio de aplicações de regras, tomar decisões e responsabilizar-se por elas, ajudar seus alunos a desenvolverem compreensões refletidas e criar oportunidades para novas compreensões das matérias (CORRADINI; MIZUKAMI, 2011, p. 56).

A formação de educadores do campo faz parte do embate político dos movimentos sociais que buscam a valorização da identidade dos homens e mulheres do campo, como afirma Arroyo (2012, p. 361) "a concepção e a política de formação de professores do campo vão se construindo na conformação da educação do campo". 
Outra unidade, com $25 \%$ referente a ser professor nos territórios rurais, pressupõe enfrentar dificuldades:

[...] Ser professor nos territórios eu sei que é muito difícil, como a gente vê, as atividades e recursos para nós aqui, no caso é muito difícil, a gente que tem que comprar, têm muitos desafios, ser professor da zona azul rural a gente enfrenta muitas dificuldades principalmente de materiais didáticos, materiais pedagógicos, mas mesmo assim eu não acho que haja muita diferença da escola do campo para ir para escola da cidade, porque os professores daqui da zona do campo eles desempenham, apesar dos desafios, que tem muitos desafios, mas eles procuram dar o melhor de si. Nós aqui principalmente, às vezes não temos material didático, mas a gente compra, se a gente não sabe fazer a gente manda (risos), mas tem aquele material e eu sei que as dificuldades são tantas, o professor da zona rural ele tem que ser um professor guerreiro, porque não é fácil, as dificuldades são tantas para enfrentar perante os alunos, perante a comunidade e muitas vezes não tem recurso, o recurso é pouquinho [...] e o recurso que vem é pelo número de alunos, então é pouquinho para se trabalhar tudo isso na escola, principalmente material didático que se usa muito na sala de aula (BEM-TE$V I)$.

[...] desde quando eu comecei minha vida estudantil e profissional foi aqui no campo, então a gente sabe que tem muitas dificuldades, mas também não são tantas, então um dos pontos é esse, é a falta de assistência dos pais, alguns pais que deixam os filhos e vão para colônia e as crianças ficam sozinhas. Questão de comportamento também, que a gente sofre mais em decorrência disso, também existe carência, muitos pais carentes (MARIA).

A professora Bem-te-vi fez um relato de como é difícil ser docente nos territórios rurais pelas dificuldades enfrentadas e pela ausência de recursos didáticos e pedagógicos, de tal modo que o professor procura dar o melhor de si na busca da superação desses desafios. O educador se reinventa para não deixar os alunos sem atividades. Para Gerone Júnior e Hage (2013) é notória a precariedade das escolas ribeirinhas que dificultam o desenvolvimento da ação pedagógica. Em um estudo realizado por Fernandes, Akkari e Silva (2011, p. 85) verificaram que nas escolas públicas há,

[...] uma grande carência de recursos, em especial na zona rural, onde os recursos enviados para as escolas são insuficientes para suprir suas necessidades. Muitas vezes a escola tem que buscar outras fontes de recursos apelando para os pais e para a própria comunidade.

Na fala da professora Maria há outra dificuldade existente, a relação com as famílias, pois as mesmas sobrevivem da agricultura e da pesca, com isso, deixam os filhos sem esse acompanhamento familiar, muitas delas têm carências de ordem financeira. Sobre isso, Gerone Júnior e Hage (2013, p. 27), afirmam que "a realidade social que se encontram boa parte das comunidades ribeirinhas é de significativa precariedade. Não é fácil estar em uma sala de aula enquanto a fome, a carência de alimentos no lar, as doenças [...] batem à porta". 
Segundo Perez (2012) tanto a escola quanto a família realizam suas funções, entretanto recebem influências por condicionamentos referentes ao contexto histórico-social, diversas transformações percebidas nos desígnios do âmbito familiar resultam de processos sociais, históricos, culturais e econômicos.

Todavia é importante ressaltar o que afirmam os autores Fernandes, Akkari e Silva (2011) quando em suas pesquisas asseguram que os professores percebem que algumas famílias/pais se omitem em colaborar com a educação dos filhos no que se refere à relação/parceria com a escola, em outras palavras, os docentes alegam que tais famílias apresentam desleixo, sobretudo, nas escolas públicas, e adjudicam a educação dos filhos aos professores.

Apesar de todas as problemáticas que persistem no contexto dos territórios rurais, $25 \%$ das professoras afirmam que se sentem bem trabalhando no campo, pois tem contato com a natureza. Essa comodidade é enfatizada pela professora Maria:

[...] não posso dizer assim, que já é uma escola, que seja tão distante das coisas modernas. Nós temos internet, nós temos computadores, a própria estrutura da escola, não é tão precária, nós temos ginásio, nós temos uma estrutura muito boa, eu considero, se a gente for comparar com uma escola da cidade do município de Santarém, eu vejo que nossa escola ela está boa.

As professoras consideram ser muito relevante as suas funções de docentes nos territórios rurais, não negam os desafios, bem como salientam as especificidades de se trabalhar nesses locais.

Vale destacar que seis unidades de significado receberam cada uma delas um percentual de $12 \%$, as professoras Pajurá, Mary, Helen, Eva das Rosas e Violeta afirmaram que ser professor no campo é significativo, pois - os alunos daqui são totalmente diferentes; a gente tem espaço de caminhar da casa da gente sem susto, sem ser assaltada; um lugar bacana a escola do campo; é como se fosse em qualquer lugar; nossas aulas hoje no campo já estão muito diferenciadas; conhecer a criança no seu dia a dia, cada criança é uma criança.

É importante salientar que trabalhar as peculiaridades do camponês, não significa isolá-lo do contexto global, "os atores da escola do campo também buscam um aprendizado que lhes possa proporcionar uma visão ampliada da realidade, na solução de problemas que surgem no seu existir como um ser que vive em coletividade" (SANTOS; ALMEIDA, 2012, p. 146).

Na concepção da professora Mary, ser professor no campo - a gente tem espaço de caminhar da casa da gente sem susto, sem ser assaltada, ela justificou que se pode andar com 
segurança, sem ter a preocupação de sofrer algum tipo de violência no caminho para a escola, além disso, ela destaca também que na cidade, as pessoas vivem a agitação própria dos centros urbanos. Por essas razões, ela considera o campo como "um lugar bacana" onde se tem mais tranquilidade no ir e vir.

No discurso da professora Helen, estar docente no campo - é como se fosse em qualquer lugar. Sobre isso, ela não está negando a singularidade do território rural, o ponto de análise dela é que se o professor estiver qualificado ele consegue atuar em diferentes contextos:

[...] se nós professores estamos sendo preparados, nós sempre estamos em formação, então nós podemos fazer a mesma coisa que em outro lado uma cidade faz certo, não vai todos os recursos tecnológicos, mas nós podemos renovar os nossos conhecimentos e colocar para nosso aluno (HELEN).

Sobre a analogia campo e cidade, Santos; Almeida (2012, p. 144), afirmam que:

[...] O cotidiano da escola do campo não difere da escola da cidade, onde os sujeitos presentes são as crianças, os jovens e os adultos, evidentemente estas pessoas possuem particularidades distintas quanto ao ambiente em que vivem em relação àqueles que moram na cidade.

Sobre a unidade de significado - nossas aulas hoje no campo já estão muito diferenciadas - assim a professora Eva das Rosas define sua atuação no campo.

As crianças já têm muito, assim, depois que chegou a nossa energia, ele já tem muito acesso aos meios de comunicação, então nossas aulas hoje do campo já estão muito diferenciadas de uma atividade de outras escolas [...] eles já têm muito conhecimento, eles já trazem um reconhecimento, um vasto conhecimento de casa, da família, da sua comunidade [...] é fundamental esse conhecimento das crianças, porque eles já trazem, assim, eles já sabem falar tudo aquilo que acontece, principalmente, o que acontece dentro da família deles, a gente sabe a maioria dos alunos contam para gente aquilo que acontece na família.

A professora observa que no campo as crianças já têm acesso aos meios de comunicação e, consequentemente, elas estão ficando mais informadas, pois, segundo a professora, já trazem conhecimento de casa.

[...] os processos educacionais devem ser concebidos sob uma perspectiva integradora que inclui as seguintes noções: o ensino e a aprendizagem são processos inter-relacionados; as pessoas constroem seu próprio conhecimento com base em conhecimentos anteriores e em suas experiências pessoais; para auxiliar os alunos a construir o seu próprio conhecimento é necessária maior compreensão sobre os processos metacognitivos e sua aplicação; o ensino reflexivo exige apoio e um tipo específico de estruturação para que possa ser adotado pelos professores e, em conseguinte, pelos seus formadores (TANCREDI; REALI, 2011, p. 35). 
Ensinar e aprender é um processo e, como tal, não pode ser implementado separadamente, a fragmentação é uma estratégia que não forma o sujeito integral, trazendo consequências para a vida do aprendiz, uma vez que o aprendizado adquirido na escola fica sem significado para suas vivências e inquietações cotidianas. Sobre isso, as autoras Corradini e Mizukami (2011, p. 57) destacam que:

Não podemos privilegiar o acesso ao conhecimento em detrimento de outras formas de aprendizagem. A educação é um todo, que deve ser considerada em sua plenitude. Os primeiros conhecimentos são enriquecidos e aprofundados, para que as pessoas possam adaptar-se a um mundo de mudanças.

Essas mudanças exigem que "todos os processos de aprendizagem, englobados, levam as pessoas, desde a infância até o fim da vida, a um conhecimento dinâmico do mundo, dos outros e de si mesmas [...]” (CORRADINI E MIZUKAMI, 2011, p. 57).

Assim, torna-se necessário enfatizar que o conhecimento não se alcança somente na escola, a criança traz consigo uma gama de informações que são adquiridas a partir da convivência nos diferentes grupos sociais, sendo que o primeiro deles é a família, e isso ocorre independentemente do acesso aos meios de comunicação, já que se aprende por meio das manifestações culturais. Para Lima (2013, p. 96), os “[...] saberes estão presentes no dia a dia dos ribeirinhos, em suas relações com diferentes espaços em ações ou comportamentos relacionados à terra, à mata e às águas".

A professora Violeta afirma que ser professor no campo é poder conhecer a criança no seu dia a dia, cada criança é uma criança:

[...] você tem que ter amor e [...] Dom, porque nós sabemos que cada criança é uma criança, então para mim ser professor, eu tenho que saber, eu tenho que conhecer minha criança no meu dia a dia, eu tenho que saber de onde ele vem, o que fez, como é a família. Porque cada um, ele tem uma distância que é diferente do outro, então tudo isso vai repercutir lá no aprendizado dele aqui e vai [...] desmoronar aqui no meu trabalho se eu não conhecer a rotina do meu aluno, eu não vou poder desenvolver um bom trabalho com ele (Pesquisadora: A senhora procura conhecer antes de começar suas aulas?) antes de começar as aulas, isso eu faço logo na primeira semana na hora que eu recebo a criança eu começo a fazer essa entrevista com ela, aí eu começo a conhecer, onde mora, como é sua casa, como é a família, qual é o percurso que você faz? por onde você vem? Será que não dá de você fazer outro percurso que é muito mais curto? aí tudo isso daqui é um trabalho que a gente vai desenvolvendo, que cada ano a gente vai mudando e vai recolhendo crianças diferentes e (Pesquisadora: eles vêm de diferentes realidades $e$ diferentes distâncias?) diferentes realidades $e$ diferentes distâncias (VIOLETA).

Como relatado pela professora, ela estabelece a relação com seus alunos, desenvolvendo estratégias de conhecer o outro a cada início de ano letivo, inclusive com esse 
mapeamento ela identifica os estudantes que possuem ou não o acompanhamento da família. Após esse processo, ela planeja como executará as atividades que atenda às necessidades dos alunos.

Sobre a postura que deve ser adota pelos professores, as autoras Corradini e Mizukami (2011) argumentam que o fracasso escolar não deve ser atribuído apenas ao aluno, é necessário considerar os diversos fatores que inviabilizam o sucesso do desenvolvimento educacional. O aluno é o construtor do seu conhecimento e o professor é o mediador desse processo, devendo conduzi-lo de forma responsável, competente e intencional. Ou seja, o docente é um parceiro que auxilia o aprendiz nessa construção. Por isso, é importante que o educador identifique as dificuldades de seus alunos para tentar superá-las.

Ao conceber a importância da participação dos pais na escola, a professora Violeta sempre realiza um projeto denominado "sacola viajante", nessa sacola o aluno leva um livro para sua casa, o qual deve fazer a leitura com a família e, posteriormente, socializar em sala de aula. Segundo ela, essa estratégia foi e é positiva, pois, quando a sacola não chega até a família, os pais deslocam-se até escola para saber o motivo pelo qual ela não viajou com seu filho.

Essas estratégias adotadas pelas professoras são importantes para o processo de ensino aprendizagem. É sabido que a educação pública brasileira sofre com a falta de recursos para atender as necessidades estruturais e pedagógicas das escolas, causando um entrave na implementação de práticas pedagógicas. Porém, as escolas e os professores não podem desistir do aluno, pois este, apesar das dificuldades, deposita muita esperança neles em obter um futuro melhor para si.

Vale lembrar que "aos educadores e educadoras cabe a reflexão de que reavivar as brasas dormentes do objetivo de vida é acima de tudo reconhecer a força propulsora dos sonhos de cada um, portanto, seguir adiante é o maior compromisso na atitude de educar" (COUTO, 2008, p. 84).

\section{Considerações finais}

A pesquisa que objetivou investigar a prática docente de professoras que atuam na Educação do Campo na região Amazônica sob a perspectiva da corporeidade, concluiu que as professoras dialogam com a corporeidade nas suas práticas docentes. Essa afirmativa é identificada no momento em que elas compreendem a condição de sujeitos corporais em sala aula, de sujeitos que possuem história e conhecimento antes de chegar na escola. Esse conhecimento é formado por meio das vivências culturais, e a corporeidade tem como premissa, 
a aprendizagem significativa da cultura, pois é através dela que nos tornamos seres humanos, e é neste sentido que se configura a ideia de ser e estar no mundo.

As professoras, participantes da pesquisa, entendem que seus alunos não são um protótipo para se construir a sociedade ideal e percebem que eles não têm os mesmos anseios e problemas. Segundo elas, cada criança é uma criança que possui realidades e não uma única realidade, por isso é tão importante para a professora Violeta diagnosticar a necessidade de cada criança, identificando suas carências, sonhos e dificuldades.

Concluiu-se, que elas, as professoras, ao buscarem a parceria da família compreendem a importância desta ação, inclusive para fortalecer o que estão trabalhando em sala de aula, além de fazer parte da formação das crianças. Para outras professoras, essa relação família e escola ainda é um desafio, principalmente pelas questões financeiras, pois as atividades econômicas desenvolvidas pelas famílias dificultam o acompanhamento dos filhos na escola, uma vez que trabalham com a agricultura. Contudo, isso não foi pretexto para justificar que a família é ausente, decadência da educação ou para não esforçar-se no exercício da docência. Ao contrário, criaram projetos para resgatar o cuidado da família com a criança na escola, como por exemplo, a sacola viajante.

Para as professoras, o aprendizado da criança depende da ação do professor, e, um dos elementos dentro da corporeidade é a defesa de que o ensino e aprendizagem estão conectados.

Cabe ressaltar que a corporeidade aprendente na prática docente, se manifesta também quando o professor mostra, por meio de um processo reflexivo, a capacidade que cada aluno tem de se expressar subjetivamente, e que ela só será objetivada se cada um se reconhecer capaz de executá-la. Mas para que isso ocorra, o aprendizado deve ser significativo e, ele depende do sentido que o professor dá ao aluno em sala de aula.

Sobre isso Freire (2016, p. 43) constata que "às vezes, mal se imagina o que pode passar a representar na vida de um aluno um simples gesto do professor". Nesta afirmativa, ele quer destacar a importância do professor na visão do aluno e, talvez, o professor nem o percebe ou muitas vezes, não consegue mensurar quanto "[...] pode um gesto aparentemente insignificante valer como força formadora ou como contribuição à assunção do educando por si mesmo" (FREIRE, 2016, p. 43).

As professoras pesquisadas poderiam adotar o modelo tradicional de ensinar que em tese é mais fácil, pois não tem o trabalho de fazer o aluno refletir criticamente, porque isso dá mais trabalho, mas resolveram explorar a realidade do aluno e a conjugaram com outras realidades fora do espaço de convivência diária deles. Elas acreditam que ser docente no campo 
é contribuir com a formação e na reafirmação da identidade dos sujeitos do campo, impulsionando-os ao desenvolvimento crítico, na busca de superação dos desafios sociais, econômicos e políticos que se concentram em seus territórios rurais.

Constatou-se, portanto que a prática docente das professoras camponesas é vivência corporal, no sentido de entender e valorizar o outro (aluno/aluna) em suas possibilidades, entendendo possíveis limitações, fragilidades, carências e necessidades como também fortalecendo e estimulando potencialidades, virtudes, qualidades e talentos, conjugando sensibilidade e inteligibilidade num contexto do campo amazônico que demonstra capacidade de revelar e gerar mais conhecimentos acerca da realidade de vida das pessoas e das relações que ocorrem entre elas, com os outros seres, com as coisas, com o ambiente e com o mundo.

\section{REFERENCIAS}

ARROYO, Miguel Gonzalez. Formação de educadores do campo. In: CALDART, Roseli Salete; PEREIRA Isabel Brasil; ALENTEJANO, Paulo; FRIGOTTO, Gaudêncio (Orgs). Dicionário da Educação do Campo. Rio de Janeiro, São Paulo: Escola Politécnica de Saúde Joaquim Venâncio, Expressão Popular, 2012.

ASSMANN, Hugo. Reencantar a educação: rumo à sociedade aprendente. 12. ed. Petrópolis, RJ: Vozes, 2012.

BAGGIO, André; VIEIRA, Péricles, Saremba Vieira. Novos paradigmas e educação: física, antropologia, pedagogia, brincadeira. Curitiba: Editora CRV, 2009.

CALDART, Roseli Salete. Sobre Educação do Campo. In: SANTOS, Clarice Aparecida dos (Org.). Educação do Campo: campo- políticas públicas - educação/. - Brasília: INCRA; MDA. 2008109 p.: 19 cm - (NEAD Especial: 10).

CORRADINI, Suely Nercessian; MIZUKAMI, Maria da Graça Nicoletti. Formação docente: o profissional da sociedade contemporânea. Revista EXITUS | Volume 01 | Número 01 | Jul./Dez. 2011. Disponível em <http://www.ufopa.edu.br/portaldeperiodicos/index.php /revistaexitus/article/view/205> acesso em 14 de abril de 2020.

COSTA, Ana Sheila Fernandes; AKKARI Abdeljalil; SILVA, Rossana Valéria Souza. Educação básica no Brasil: políticas públicas e qualidade. Práxis Educacional. Vitória da Conquista. v. 7, n. 11 p. 73-93 jul./dez. 2011. Disponível em <http://periodicos2.uesb.br/ index.php/praxis/article/view/666> acesso em 14 de abril de 2020.

COUTO, Hergos Ritor Fróes de. A criança e as manifestações lúdicas de rua e suas relações com a educação física escolar. Piracicaba, 2008.131 p. Dissertação (Mestrado em Educação Física). Núcleo de Pedagogia do Movimento, Corporeidade e Lazer, Universidade Metodista de Piracicaba. Disponível em <https://www.unimep.br/phpg/ bibdig/pdfs/2006/ UWRIFYTSWRJB.pdf> acesso em 30 jun 2015.

CUNHA, Úrsula Nascimento de Sousa. Leitura e escrita no ensino fundamental, (res) significando o trabalho com gêneros textuais. Práxis Educacional. Vitória da Conquista. v. 6, 
n. 8 p. 123-138 jan./jun. 2010. Disponível em <http://periodicos2.uesb.br/ index.php/praxis/article/view/621> acesso em 14 de abril de 2020.

FONSECA, Rosa Maria; MOURÃO, Arminda Rachel Botelho. A educação do campo: uma realidade construída historicamente. In: GHEDIN, Evandro (Org). Educação do Campo: epistemologias e práticas. $1^{a}$ ed. - São Paulo: Cortez, 2012.

FREIRE, Paulo. Pedagogia da autonomia: saberes necessário à prática educativa. $54^{\mathrm{a}} \mathrm{ed}-$ Rio de Janeiro: Paz e Terra, 2016.

GOELLNER, S. A produção cultural do corpo. In: Louro, G. NECKEL, J. GOELLNER, S. (orgs.). Corpo, gênero e sexualidade: um debate contemporâneo na educação. Petrópolis, RJ. Vozes, 2003.

GERONE JUNIOR, Acyr de; HAGE, Salomão Antonio Mufarrej. Ser professor ribeirinho: os desafios que emergem da educação e da ação pedagógica em escolas ribeirinhas da Amazônia. In: ABREU, Waldir Ferreira de; OLIVEIRA, Damião Bezerra; SILVA, Érbio dos Santos (Orgs). Educação ribeirinha: saberes, vivencias e formação no campo. $2^{\mathrm{a}} \mathrm{Ed}$. GEPEIF-UFPA, Belém, 2013.

INFORSATO, E. C. A Educação entre o controle e a libertação do corpo. In: MOREIRA, W.W (Org). Século XXI: a era do corpo ativo. Campinas: Papirus, 2006. Cap. 5 p. 91 -108.

LIMA, Natamias Lopes de. Saberes culturais e modos de vida de ribeirinhos: a relação com o currículo em ação. In: ABREU, Waldir Ferreira de; OLIVEIRA, Damião Bezerra; SILVA, Érbio dos Santos (Orgs). Educação ribeirinha: saberes, vivencias e formação no campo. $2^{\mathrm{a}}$ Ed. GEPEIF-UFPA, Belém, 2013.

MOREIRA, W.W. et. al. Corporeidade aprendente: a complexidade do aprender a viver. In: (Org.). Século XXI: a era do corpo ativo. Campinas: Papirus, 2006. p. 134-157.

MOREIRA, W.W.; SIMÕES, R.; PORTO, E. Análise de conteúdo: técnica de elaboração e análise de unidades de significado. R. bras. Ci e Mov. 2005; 13(4): 107-114.

NOBREGA, Terezinha Petrucia da. Uma fenomenologia do corpo. - São Paulo: Editora livraria da Física, 2010. (Coleção contextos da ciência).

OLIVEIRA, I. A. SANTOS, T. R. L. A cultura amazônica em práticas pedagógicas e educadores populares. 2007. Disponível em: http://30reuniao.anped.org.br/trabalhos/GT063039--Int.pdf Acesso em dez 2017.

PEREZ, Marcia Cristina Argenti. Infância e escolarização: discutindo a relação família, escola e as especificidades da infância na escola. Práxis Educacional. Vitória da Conquista. v. 8, n. 12 p. 11-25 jan./jun. 2012. Disponível em <http://periodicos2.uesb.br/ index.php/praxis/article/view/684> acesso em 14 de abril de 2020.

PERRENOUD, P. Ofício de aluno e sentido do trabalho escolar. Portugal: Porto, 1995.

SANT’ANNA, Denise Bernuzzi. É possível realizar uma história do corpo? In: SOARES, Carmem Lucia (Org). Corpo e história. Campinas, SP: Autores Associados, 2001.

SILVA, Alexandre Fernando da; FERREIRA, José Heleno; VIERA, Carlos Alexandre. O ensino de ciências no ensino fundamental e médio: reflexões e perspectivas sobre a educação 
transformadora. Revista EXITUS, Santarém/PA, Vol. 7, N² 2, p. 283-304, Maio/Ago 2017. Disponível em <http://www.ufopa.edu.br/portaldeperiodicos/index.php/revistaexitus/article/ view/314> acesso em 14 de abril de 2020.

SILVA, Nilson Robson Guedes. Gestão escolar democrática: Uma contextualização do tema. Práxis Educacional. Vitória da Conquista. v. 5, n. 6 p. 91-106 jan./jun. 2009. Disponível em <http://periodicos2.uesb.br/index.php/praxis/article/view/590> acesso em 14 de abril de 2020.

TANCREDI, Regina Maria Simões Puccinelli; REALI, Aline Maria de Medeiros Rodrigues. O que um mentor precisa saber? Ou: sobre a necessidade de um mentor construir uma visão multifocal. Revista EXITUS. Volume 01. Número 01. Jul./Dez. 2011. Disponível em <http://www.ufopa.edu.br/portaldeperiodicos/index.php/revistaexitus/article/view/203> acesso em 14 de abril de 2020.

\section{SOBRE OS AUTORES:}

\section{Rosenilma Branco Rodrigues}

Mestra em Educação (UFOPA); Professora de filosofia na Secretaria Estadual de Educação do Estado do Pará - Brasil; É integrante do Grupo de Pesquisa Cognições e Práticas Formativas Educacionais em Espaços Escolares e Não-Escolares/UFOPA; E-mail: rosebrancor@yahoo.com.br

(iD http://orcid.org/0000-0003-2058-4341

\section{Hergos Ritor Fróes de Couto}

Pós-doutor em Desporto pela Faculdade de Desporto da Universidade do Porto/Portugal; Doutorado em Educação pela Universidade Nove de Julho; Professor efetivo da Universidade Federal do Oeste do Pará (UFOPA), na categoria Adjunto IV; Professor no Programa de PósGraduação em Educação - UFOPA; É integrante do Grupo de Pesquisa Cognições e Práticas Formativas Educacionais em Espaços Escolares e Não-Escolares/UFOPA; E-mail: hergos@hotmail.com

(iD) http://orcid.org/0000-0002-0101-4012

Recebido em: 27 de março de 2019

Aprovado em: 03 de maio de 2020

Publicado em: 01 de julho de 2020 